\title{
Office management of patients with diastolic heart failure
}

\author{
Katina Tzanetos MD MSc, Derek Leong BScPhm, Robert C. Wu MD MSc
}

\section{The case}

You have a 76-year-old patient with heart failure that was diagnosed 2 months ago. She has a history of hypertension, which is being treated with amlodipine. On her initial visit 2 months previously, you prescribed furosemide $40 \mathrm{mg}$ once daily. She responded favourably with a decrease in some symptoms. The patient has returned for follow-up. She denies chest pain but continues to experience mild dyspnea on climbing more than 1 flight of stairs. Her blood pressure is $130 / 80 \mathrm{~mm} \mathrm{Hg}$, her heart rate is 79 beats/min and regular, and her jugular venous pressure is $5 \mathrm{~cm}$ above the sternal angle. She has a fourth heart sound, mild rales at the base of both lungs and mild edema in both ankles. Her hemoglobin, glucose and creatinine levels are normal. An electrocardiogram shows sinus rhythm with left ventricular hypertrophy; a cardiac perfusion scan is normal. A 2-dimensional echocardiogram shows a normal left ventricular ejection fraction, a thickened left ventricle and impaired left ventricular relaxation. How would you proceed with management of this patient?

$\mathrm{H}$ eart failure is defined by the Canadian Cardiovascular Society as "a complex syndrome in which abnormal heart function results in, or increases the subsequent risk of, clinical symptoms and signs of low cardiac output and/or pulmonary or systemic congestion." Traditionally, heart failure has been associated with systolic pump dysfunction - that is, the failure of the left ventricle to eject blood into the aorta. ${ }^{2}$ Recently though, diastolic dysfunction has been recognized increasingly as a cause of much of the burden of heart failure. ${ }^{3}$ Diastolic dysfunction has been described as inadequate filling of the left ventricle during diastole owing to impaired left ventricular relaxation. ${ }^{2,4}$ When heart failure ensues in this setting and the ejection fraction remains normal or near normal, it is termed diastolic heart failure. ${ }^{5,6}$

Both the term "diastolic heart failure" and the method used to diagnose the condition are subject to ambiguity and debate in the literature. ${ }^{5,7}$ Often, the phrase "heart failure with preserved systolic function" is used interchangeably with "diastolic heart failure."' This reflects a presumption that patients with heart failure and preserved ejection fraction have diastolic dysfunction even in the absence of evidence from an objective assessment of left ventricular function. ${ }^{8}$ The question of whether diastolic abnormalities must be proven before making a diagnosis of diastolic heart failure is debatable. What the best modality of cardiac imaging is to accomplish this is also

\section{Key points}

- Diastolic heart failure is increasingly recognized as an important clinical syndrome, but the criteria for diagnosis are subject to debate.

- Large, high-quality randomized trials of angiotensinconverting-enzyme inhibitors, $\beta$-blockers, angiotensinreceptor blockers and digoxin do not show any improvement in survival rates.

- Use of angiotensin-receptor blockers reduces the rate of hospital admissions due to heart failure but is associated with an increased risk of hypotension, renal failure and hyperkalemia.

- In the absence of evidence-based interventions for diastolic heart failure, clinicians should focus on treating comorbidities, such as hypertension, atrial fibrillation and coronary artery disease.

debatable. ${ }^{5}$ Diseases related to pericardial or valvular defects and systemic conditions (e.g., renal failure and anemia) that can lead to heart failure in the presence of a normal ejection fraction can also fall under the umbrella of "heart failure with preserved systolic function.." Finally, the definitions of both "diastolic heart failure" and "heart failure with preserved ejection fraction" require a normal or near normal ejection fraction. ${ }^{2,4}$ Near normal, however, can include ejection fractions ranging from $35 \%$ to $55 \%$ depending on the source. ${ }^{2,8}$

Various groups have proposed criteria for the diagnosis of diastolic heart failure..$^{5,-11}$ All acknowledge that the condition cannot be distinguished from systolic heart failure on the basis of symptoms, physical examination, chest radiography or electrocardiography. ${ }^{3}$ They also all agree that signs and symptoms compatible with heart failure must be present and that a normal ejection fraction must be demonstrated.

Practical recommendations for diagnosis have been made by both the Canadian Cardiovascular Society ${ }^{1}$ and the American College of Cardiology in a joint effort with the American Heart Association. ${ }^{9}$ According to these groups, a diagnosis of diastolic heart failure should be considered when there are signs and symptoms of heart failure (e.g., fatigue, pulmonary congestion and dependent edema) and when there is objective evidence of a normal or near normal ejection fraction, either with or without demonstrated diastolic abnormalities, and without valvular defects. ${ }^{1.9}$ Patients should also be free of pericardial disease or a systemic condition (e.g., anemia or renal failure)

From the Department of Medicine (Tzanetos, Wu), University of Toronto and the Division of General Internal Medicine (Tzanetos, Wu) and Department of Pharmacy (Leong), University Health Network, Toronto, Ont. 
that could explain their heart failure. This is the definition of diastolic heart failure that we have adopted for our review.

\section{The challenge of defining the epidemiology of diastolic heart failure}

Not only do the definition and diagnostic criteria of diastolic heart failure vary in the literature, but large, prospective epidemiologic studies have not differentiated between systolic and diastolic heart failure. ${ }^{12}$ Identifying high-quality, uniform studies of diastolic heart failure on which to base precise conclusions regarding prevalence, risk factors and prognosis is therefore difficult. ${ }^{8}$ To deal with this deficiency, reviews of primary studies most often report mean estimates with wide ranges and include a call for further studies..$^{13}$

\section{How common is diastolic heart failure?}

The increasing size of the elderly population in North America is causing the number of people affected by the disease to increase dramatically. This increase has given rise to a perception that heart failure is a growing epidemic despite its stable incidence. ${ }^{13,14}$ Diastolic heart failure is common and is responsible for a large proportion of society's health care costs. ${ }^{1.5}$ A recent review of primary epidemiologic studies of its prevalence across various communities suggests that diastolic heart failure accounts for $54 \%$ of all cases of heart failure on average, with a range of $40 \%-74 \% .^{13,16-20}$ This wide range likely reflects not only the unique characteristics of the communities investigated, but also the lack of a consistent definition of diastolic heart failure and the variability of the cutoff point for what is considered a normal or near normal ejection fraction..$^{2,22}$

The factors most often found to be associated with the development of diastolic heart failure include increasing age, female sex, hypertension and atrial fibrillation. $.^{3,18,23-25} \mathrm{Al}-$ though there is some discrepancy regarding the risk posed by coronary artery disease, its prevalence among patients with diastolic heart failure is generally lower than it is among patients with systolic heart failure and higher than it is among healthy controls..$^{13}$ A recent investigation of 2802 admissions because of heart failure to 103 Ontario hospitals compared patients with diastolic heart failure (ejection fraction $>50 \%$ ) and systolic heart failure (ejection fraction $<40 \%$ ). ${ }^{3}$ The study found significant differences between the 2 groups. Patients with diastolic heart failure were older ( 75 years v. 72 years), more often female (66\% v. $37 \%)$ and more likely to have a history of hypertension $(55 \%$ v. $49 \%)$ and atrial fibrillation (32\% v. $24 \%)$. However, they were less likely to have coronary artery disease (36\% v. $49 \%)$ and cardiac risk factors including diabetes, hyperlipidemia and a history of smoking. Another analysis involving 4596 patients in hospital confirmed those findings and identified further significant associations with diastolic heart failure, including higher body mass index and obesity, and lower hemoglobin level on admission as compared with patients who had systolic heart failure. ${ }^{25}$ Reports of patients in the community with diastolic heart failure have made similar observations..$^{16,23}$

\section{What is the prognosis of patients with diastolic heart failure?}

Whether diastolic heart failure leads to a similar or better outcome than systolic heart failure is still unknown. Earlier data from the 1980s and 1990s suggested that diastolic heart failure carries a better prognosis than systolic heart failure. ${ }^{16} \mathrm{Par}-$ ticipants in the Framingham Heart Study, for example, were followed for 6 years: those with diastolic heart failure were found to have an annual mortality of $9 \%$, as compared with $18 \%$ among those with systolic heart failure. ${ }^{16}$ More recent literature, however, suggests that mortality for the 2 conditions may be similar. ${ }^{13,26}$ In a study involving Ontario residents admitted to hospital, mortality at 1 year was $22 \%$ among those with diastolic heart failure and $25 \%$ among those with systolic heart failure - a nonsignificant difference. ${ }^{3}$ Similarly, in the community study of Minnesota residents with heart failure, the 1-year mortality was $29 \%$ among those with diastolic heart failure. ${ }^{23}$ The reason for the difference between older and more recent studies is unclear. It may be due to differences in the diagnostic criteria used and the clinical characteristics of the patients included. ${ }^{26}$ The morbidity of diastolic heart failure is high, paralleling that of systolic heart failure in terms of required outpatient visits and a 1-year hospital readmission rate that approaches $50 \% .5,17$

\section{Box 1: Systematic literature search}

To identify articles that examined pharmacologic or nonpharmacologic therapies for the treatment of diastolic heart failure in the outpatient setting, we conducted searches of MEDLINE (1950 to January 2008), the Cochrane Database of Systematic Reviews, the Cochrane Database of Abstracts of Reviews of Effects and the Cochrane Central Register of Controlled Trials. Details of the search strategy appear in Appendix 1.*

We included studies if they met the following inclusion criteria:

- Randomized controlled trials and meta-analyses that used clinically significant outcome measures (e.g., mortality, morbidity and quality of life) as primary or secondary outcomes.

- Study participants had clinically apparent heart failure and a left ventricular ejection fraction that was confirmed to be $\geq 40 \%$ by echocardiography or an equivalent modality of cardiac imaging. We used this cutoff point for the lower limit of left ventricular ejection fraction so that we could include studies with a broad definition of diastolic heart failure while still excluding studies of definite systolic heart failure as defined by major trials and recent guidelines. ${ }^{1,30,31}$

- Studies that had both patients with systolic heart failure and those with diastolic heart failure, only if the patients with diastolic heart failure were in an easily identifiable subgroup and their data analyzed separately.

Our search identified 640 articles, of which 14 randomized controlled trials (there were no meta-analyses) ultimately met our inclusion criteria. Details of the included studies appear in Table 1 and in Appendices 2-4.*

*Appendices are available at www.cmaj.ca/cgi/content/full/180/5/520/DC1. 


\section{Why is it important to differentiate diastolic and systolic heart failure?}

Distinguishing diastolic and systolic heart failure in patients is important because the strategies for their management may differ. A vast and sound body of evidence exists to guide clinicians in managing systolic heart failure. However, treatment of diastolic heart failure may not be easily extrapolated from these data and has yet to be firmly accepted.

\section{How should patients with diastolic heart failure be managed?}

Because fewer large clinical trials have addressed the management of diastolic heart failure compared with those addressing systolic heart failure, most guidelines on the topic have admittedly made their recommendations in the absence of evidence. ${ }^{1,9}$ Many reviews have resorted to a physiologic understanding of diastolic dysfunction to draw conclusions. ${ }^{27}$

Table 1: Details of randomized trials of therapies for diastolic heart failure (part 1)

\begin{tabular}{|c|c|c|c|c|}
\hline Study & Therapy & Outcome measures & $\begin{array}{l}\text { Length of } \\
\text { follow-up }\end{array}$ & Results \\
\hline
\end{tabular}

\begin{tabular}{|c|c|c|c|c|}
\hline $\begin{array}{l}\text { ACE inhibitors and } \\
\text { angiotensin-receptor } \\
\text { blockers }\end{array}$ & & & & \\
\hline \multirow[t]{3}{*}{$\begin{array}{l}\text { Cleland et al., } \\
\text { PEP-CHF trial } \\
(n=850)\end{array}$} & \multirow[t]{3}{*}{ Perindopril } & $\begin{array}{l}\text { Primary: composite outcome of all- } \\
\text { cause mortality or unplanned hospital } \\
\text { admission because of heart failure }\end{array}$ & \multirow[t]{3}{*}{ Mean 26.2 mo } & \multirow{2}{*}{$\begin{array}{l}\text { Primary: no difference between } \\
\text { study groups (treatment } 23.6 \% \\
\text { v. placebo } 25.1 \% ; \text { HR } 0.92,95 \% \\
\text { Cl } 0.70-1.21 ; p=0.545 \text { ) }\end{array}$} \\
\hline & & \multirow[b]{2}{*}{$\begin{array}{l}\text { Secondary: all-cause mortality; } \\
\text { cardiovascular-related mortality; all- } \\
\text { cause hospital admission; unplanned } \\
\text { hospital admission because of heart } \\
\text { failure; worsening heart failure } \\
\text { requiring hospital admission or } \\
\text { increased diuretic therapy; hospital } \\
\text { admission because of cardiovascular } \\
\text { causes; change in NYHA class } \\
\text { (baseline v. } 1 \text { yr) }\end{array}$} & & \\
\hline & & & & $\begin{array}{l}\text { Secondary: improved NYHA class } \\
\text { at } 1 \text { yr with perindopril } \\
(p<0.03) \text {; no other significant } \\
\text { differences between groups. }\end{array}$ \\
\hline Lang et al. ${ }^{35}(n=12)$ & Lisinopril & $\begin{array}{l}\text { Dyspnea on walking, fatigue, } \\
\text { limitations to physical activity and } \\
\text { dyspnea at night, using visual } \\
\text { analogue scale }\end{array}$ & $\begin{array}{l}5 \text { wk before } \\
\text { and } 5 \text { wk after } \\
\text { crossover }\end{array}$ & $\begin{array}{l}\text { No differences in reported } \\
\text { symptoms between treatment } \\
\text { and control groups }\end{array}$ \\
\hline $\begin{array}{l}\text { Aronow et al. }{ }^{39} \\
(n=21)\end{array}$ & Enalapril & $\begin{array}{l}\text { NYHA class; exercise time on } \\
\text { treadmill using modified Bruce } \\
\text { protocol }\end{array}$ & $3 \mathrm{mo}$ & $\begin{array}{l}\text { NYHA class improved from } 3 \text { to } \\
2.4(p=0.005) \text { and exercise time } \\
\text { increased from } 224 \mathrm{~s} \text { to } 270 \mathrm{~s} \\
(p<0.001) \text { in treatment group; } \\
\text { no significant difference in } \\
\text { control group }\end{array}$ \\
\hline Yip et al..$^{34}(n=151)$ & $\begin{array}{l}\text { Ramipril v. } \\
\text { irbesartan v. } \\
\text { control }\end{array}$ & MLHF score; 6MWT score & $52 \mathrm{wk}$ & $\begin{array}{l}\text { No differences between } \\
\text { treatment and control groups }\end{array}$ \\
\hline $\begin{array}{l}\text { Yusuf et al., }{ }^{37} \\
\text { CHARM-preserved trial } \\
(n=3023)\end{array}$ & Candesartan & $\begin{array}{l}\text { Secondary: death from cardiovascular } \\
\text { causes, hospital admission because of } \\
\text { CHF, or nonfatal Ml; death from } \\
\text { cardiovascular causes, hospital } \\
\text { admission because of CHF, nonfatal } \\
\text { MI or nonfatal stroke; death from } \\
\text { cardiovascular causes, hospital } \\
\text { admission because of CHF, nonfatal } \\
\text { MI, nonfatal stroke or coronary } \\
\text { revascularization; all-cause death or } \\
\text { hospital admission because of CHF; } \\
\text { and new-onset diabetes }\end{array}$ & & $\begin{array}{l}\text { Harms (absolute risk increase, } \\
\% \text { ): hypotension } 1.3 \% \text {; doubling } \\
\text { of creatinine level 3\%; potassium } \\
>6 \mathrm{mmol} / \mathrm{L} 1 \%\end{array}$ \\
\hline
\end{tabular}


The few articles that do review the literature on treatment of diastolic heart failure, although evidence-based, used nonsystematic methodology for study selection or did not consider nonpharmacologic strategies. ${ }^{28,29}$ With the increasing focus on diastolic heart failure as an important problem, more studies are emerging. We conducted a systematic review of the literature on the effective drug therapies and nonpharmacologic therapies available for diastolic heart failure in the outpatient setting (details of the literature search appear in Box 1). We also propose recommendations for clinicians that are practical and evidence-based.

\section{Pharmacologic therapy}

\section{Angiotensin-converting-enzyme (ACE) inhibitors}

We found 5 randomized controlled trials examining the role of ACE inhibitors in diastolic heart failure (Table 1) (Appendices 2 and 3, available online at www.cmaj.ca/cgi/content

Table 1: Details of randomized trials of therapies for diastolic heart failure (part 2)

\begin{tabular}{llll}
\hline Study & Therapy & Lutcome measures & $\begin{array}{l}\text { Length of } \\
\text { follow-up }\end{array}$ \\
\hline
\end{tabular}

\section{$\boldsymbol{\beta}$-Blockers}

Aronow et al. ${ }^{39}$ $(n=158)$

Propranolol

All-cause mortality; combined outcome of all-cause mortality and nonfatal MI

Takeda et al. ${ }^{40}$

Carvedilol

$(n=40)$

NYHA class; exercise capacity as measured in metabolic equivalents (METs)

Flather et al., SENIORS trial $(n=2128[n=752$ with diastolic heart failure] $)^{38}$

Nebivolol

Composite of all-cause mortality or hospital admission because of cardiovascular causes

Mean $21 \mathrm{mo}$

CHF score (combined clinical and radiographic scores); exercise time using modified Bruce protocol

\section{Other \\ pharmacologic therapies}

Hung et al. $(n=15)^{42}$

Verapamil (calciumchannel blocker)

Ahmed et al., DIG

Digoxin

ancillary

$(n=988)^{41}$

Cohn et al.,

Vheft trial $(n=83)^{43}$

Nitrates and hydralazine

Composite of mortality or unplanned hospital admission because of heart failure

Mortality

$3 \mathrm{mo}$ before and 3 mo after crossover

Mean

$37 \mathrm{mo}$

Mean

$27.6 \mathrm{mo}$

Mortality $56 \%$ in treatment group and $76 \%$ in control group $(p=0.007)$. Combined outcome $59 \%$ in treatment group and $82 \%$ in control group $(p=0.002)$.

Harms: worsened heart failure $9 \%$, hypotension $5 \%$

NYHA class improvement 0.77 in treatment group v. 0.25 in placebo group $(p<0.02)$. Increase in exercise capacity of 0.69 METs in treatment group v. decrease of 0.07 METs in control group ( $p=0.01)$

For the subgroup with left ventricular ejection fraction $>40 \%$, the HR for achieving the combined outcome for treatment v. placebo was $0.83(95 \% \mathrm{Cl}$ $0.62-1.11$ )

Significant improvement in CHF scores $(p<0.05)$ and increase in exercise time from $7.4 \mathrm{~min}$ to $8.3 \mathrm{~min}$ in treatment group $(p<0.05)$. No differences in placebo group.

$20.7 \%$ in treatment group v. $24 \%$ in placebo group (HR $0.82,95 \% \mathrm{Cl} 0.63-$ $1.07 ; p=0.136$ )

$5.3 \%$ in treatment group v. $9 \%$ in placebo group (nonsignificant difference; $95 \% \mathrm{Cl}$ and $p$ value not reported)

\section{Nonpharmacologic} therapies

Galbreath et al. ${ }^{49}$

$(n=1069[n=317$

with diastolic heart

failure])

Gary et al. ${ }^{45-47}(n=32)$

Diseasemanagement program

12-wk walking program
All-cause mortality; healthrelated quality of life measured by SF-36

6MWT score; Duke Activity Status Index; MLHF score; Geriatric Depression Scale score
$18 \mathrm{mo}$

No difference in mortality or healthrelated quality of life in subgroup with diastolic heart failure $(95 \% \mathrm{Cls}$ and $p$ values not reported)

$28 w k$ $6 \mathrm{MWT}$ score improved $203 \mathrm{~m}$ in treatment group v. decrease of $92 \mathrm{~m}$ in control group $(p=0.002)$. Significant difference in MLHF and Geriatric Depression Scale scores. No difference between groups in Duke Activity Status Index.

Note: $\mathrm{ACE}=$ angiotensin-converting enzyme, $\mathrm{CHARM}=$ Candesartan in Heart failure: Assessment of Resolution of Mortality and morbidity (CHARM-preserved is the third component of this study), $\mathrm{CHF}=$ congestive heart failure, $\mathrm{Cl}=$ confidence interval, $\mathrm{HR}=$ hazard ratio, $\mathrm{MI}=\mathrm{myocardial}$ infarction, $\mathrm{MLHF}=\mathrm{Minnesota}$ Living with Heart Failure Questionnaire, NYHA = New York Heart Association, PEP-CHF = the Perindopril in Elderly People with Chronic Heart Failure Study, 6MWT =6-minute walking test, SF-36 = Medical Outcomes 36-item Short Form. 
/full/180/5/520/DC1). Of these, the trial that was largest and of the highest quality studied perindopril use for chronic heart failure in 850 elderly people. It found no difference in the composite outcome of all-cause mortality or unplanned hospital admission because of heart failure between the treatment and placebo groups after 2.1 years. ${ }^{32}$ Notably, a high percentage of participants either stopped the study treatment (40\% in the perindopril group and $36 \%$ in the placebo group) or used open-label ACE inhibitors (35\% in the perindopril group and $37 \%$ in the placebo group), which reduced the likelihood that a detectable difference would be found.

Three smaller randomized trials $(n=151,74$ and 12) that examined the effects of ramipril, quinapril or lisinopril on diastolic heart failure showed no significant difference between treatment groups and control groups in exercise capacity, quality of life or symptoms. ${ }^{33-35}$

One small study involving 21 elderly patients with diastolic heart failure and prior myocardial infarction compared enalapril plus furosemide with furosemide alone for 3 months. Patients given enalapril had an improved exercise time of 46 seconds on average on the modified Bruce protocol test $(p<0.001)$; and their New York Heart Association functional classifications improved from 3 to 2.4 on average $(p=0.005){ }^{36}$

\section{Angiotensin-receptor blockers}

We found 2 randomized trials evaluating angiotensin-receptor blockers. The higher quality of the 2 was also the largest of the 14 studies we included in our review. The CHARMPreserved Trial, the third component trial of the Candesartan in Heart failure: Assessment of Reduction in Mortality and morbidity, enrolled 3023 patients. ${ }^{37}$ For the primary composite outcome of cardiovascular-related mortality or hospital admissions because of heart failure, there was no difference between the candesartan group and the placebo group (hazard ratio [HR] $0.89,95 \%$ CI $0.77-1.03$ ). As a predefined outcome, the rate of hospital admissions because of heart failure decreased significantly (absolute risk reduction 3.3\%; $p=$ 0.017). Notably, however, adverse events requiring permanent discontinuation significantly increased in the candesartan group. The adverse events included hypotension (absolute risk increase 1.3\%), an increase in creatinine level (absolute risk increase $2.4 \%$ ) and hyperkalemia (absolute risk increase $0.9 \%)$. A smaller randomized trial $(n=151)$ comparing the addition of irbesartan to standard therapy with the use of standard therapy alone found no benefit in quality of life, scores on a 6-minute walking test or rate of hospital admission. ${ }^{34}$

\section{$\beta$-Blockers}

We found 3 randomized trials evaluating the role of $\beta$ blockers in diastolic heart failure. The largest study enrolled patients who were at least 70 years old, had a clinical history of chronic heart failure and had either been admitted to hospital because of heart failure during the 12 months before enrolment or had a documented ejection fraction of $35 \%$ or less during the 6 months before enrolment. ${ }^{38}$ In the subgroup of patients with an ejection fraction of greater than $40 \%$, there was no difference at 21 months in the nonprespecified out- come of combined all-cause mortality and hospital admission because of cardiovascular causes between those given nebivolol and those given placebo.

Two other studies of lesser quality and smaller size $(n=$ $158, n=40$ ) did find significant improvements in clinically important outcomes with $\beta$-blockers compared with standard therapy. ${ }^{39,40}$ The first study showed an absolute risk reduction of $20 \%$ in mortality with propranolol over a mean follow-up of 32 months. The second showed significant improvements in New York Heart Association functional classifications over 12 months of follow-up in the carvedilol group, from 2.37 to 1.56 on average, compared with a nonsignificant improvement, from 2.29 to 2.11 on average, in the group receiving standard therapy.

\section{Other drugs}

We found 1 randomized trial evaluating digoxin, the Digitalis Investigation Group ancillary trial..$^{41}$ This high-quality study enrolled 988 ambulatory patients with chronic heart failure, an ejection fraction greater than $45 \%$ and normal sinus rhythm at baseline. The study found no added benefit with digoxin compared with placebo. The combined primary outcomes of hospital admission or death because of heart failure were experienced by $21 \%$ in the digoxin group and $24 \%$ in the placebo arm (HR 0.82, 95\% CI 0.63-1.07).

We found a single trial of calcium-channel blockers that compared verapamil with placebo in 15 patients. At 3 months, verapamil was associated with a significant improvement in a nonstandard symptom score and a significant improvement of 54 seconds in exercise time using the modified Bruce protocol. ${ }^{42}$

We found a single trial of nitrates plus hydralazine compared with placebo in 83 patients. The study treatment was associated with a nonsignificant relative risk reduction of $41 \%$ in all-cause mortality. ${ }^{43}$ This trial was of lower quality and included only men with evidence of cardiac enlargement.

Overall, we found 4 large, high-quality studies of pharmacotherapy, but none showed any benefit in mortality or cardiovascular-related death. ${ }^{32,37,38,44}$ In terms of symptom management, angiotensin-receptor blockers have been tested the most rigorously in the largest of all of the trials we identified (CHARM-Preserved trial). ${ }^{37}$ These agents appeared to reduce the rate of hospital admissions because of heart failure. This finding was balanced, however, by an increase in adverse events such as hypotension, worsening renal function and hyperkalemia. As suggested by the Digitalis Investigation Group ancillary trial, digoxin is unlikely to be effective in managing patients with diastolic heart failure. ${ }^{41}$ The evidence for or against $\beta$-blockers, calcium-channel blockers and nitrates plus hydralazine is simply lacking, because existing trials are few and poor in quality. Similarly, the value of ACE inhibitors has yet to be investigated adequately. Although the large trial of perindopril for chronic heart failure in elderly people showed a lack of benefit, the high use of open-label ACE inhibitors may have minimized any difference in outcome between the treatment and placebo groups and diluted measurement of the drug's true value..$^{32}$

Given the lack of therapies shown to be effective in ran- 
domized trials, where should the clinician managing patients with diastolic heart failure seek advice? Clinical practice guidelines that incorporate expert opinion are likely to provide the most helpful suggestions. The Canadian Cardiovascular Society and the joint task force of the American College of Cardiology and American Heart Association make similar recommendations (Table 2). ${ }^{1,9}$ They stress the importance of treating causes of diastolic dysfunction such as hypertension and ischemia, managing comorbidities such as atrial fibrillation, and prescribing furosemide to control pulmonary and peripheral edema. These are all reasonable recommendations based on the current understanding of the pathophysiology of diastolic dysfunction.

In terms of specific pharmacotherapies, the task force of the American College of Cardiology and American Heart Association suggests that ACE inhibitors, angiotensin-receptor blockers, $\beta$-blockers and calcium channel blockers may be effective for the control of symptoms (class IIb, level C recommendation). Based on our review, the use of angiotensin-re- ceptor blockers has the most convincing evidence to support it. Clinicians should probably consider them in patients with no contraindications, while carefully monitoring for hypotension, worsening renal function and hyperkalemia. Table 3 shows the evidence-based drug information, including starting doses and contraindications, for candesartan, the only angiotensin-receptor blocker found to have clinical benefit in a large randomized trial of diastolic heart failure. These guidelines also recommend against using digoxin, which is in keeping with our findings. Any opinions on the use of $\beta$-blockers, calcium-channel blockers and ACE inhibitors are asserted in the absence of good trial data. But again, treatment with these agents seems reasonable based on knowledge of the pathophysiology of diastolic heart failure.

\section{Nonpharmacologic therapy}

We found 1 randomized trial, described in 3 articles, ${ }^{4-47}$ that studied the effects of a 12-week exercise program in 32 older women (mean age 68 years) with diastolic heart failure. The trial

Table 2: Recommendations for the management of patients with heart failure and normal left ventricular ejection fraction issued by the task force of the American College of Cardiology/American Heart Association and the Canadian Cardiovascular Society*

\begin{tabular}{ll} 
Issue & \multicolumn{1}{c}{$\begin{array}{c}\text { American College of Cardiology/ } \\
\text { American Heart Association }\end{array}$} \\
\hline Hypertension & $\begin{array}{l}\text { Physicians should control systolic and } \\
\text { diastolic hypertension, in accordance with } \\
\text { published guidelines (class I, level A } \\
\text { evidence) }\end{array}$
\end{tabular}

Atrial fibrillation: ventricular rate

Atrial fibrillation: restoration to sinus rhythm

Diuretics

Coronary revascularization

Drug therapy
Physicians should control ventricular rate in patients with atrial fibrillation (class I, level ( evidence)

Restoration and maintenance of sinus rhythm in patients with atrial fibrillation might be useful to improve symptoms (class IIb, level C evidence)

Physicians should use diuretics to control pulmonary congestion and peripheral edema (class I, level C evidence)

Coronary revascularization is reasonable in patients with coronary artery disease in whom symptomatic or demonstrable myocardial ischemia is judged to be having an adverse effect on cardiac function (class Ila, level C evidence)

The use of $\beta$-adrenergic blocking agents, angiotensin-converting-enzyme (ACE) inhibitors, angiotensin II receptor blockers or calcium-channel blockers in patients with controlled hypertension might be effective to minimize symptoms of heart failure (class IIb, level C evidence) The use of digitalis to minimize symptoms of heart failure is not well established (class IIb, level C evidence)

\section{Canadian Cardiovascular Society ${ }^{1}$}

Systolic and diastolic hypertension should be controlled in accordance with the published hypertension guidelines (class I, level A evidence)

The ventricular rate should be controlled in patients with atrial fibrillation at rest and during exercise (class I, level C evidence)

Restoration and maintenance of sinus rhythm in patients with atrial fibrillation may be considered to improve symptoms (class Ilb, level C evidence)

Diuretics should be used to control pulmonary congestion and peripheral edema (class I, level ( evidence)

Coronary artery bypass graft surgery may be considered for patients in whom symptomatic or demonstrable ischemia is judged to have an adverse affect on cardiac function (class lla, level $\mathrm{C}$ evidence)

ACE inhibitors and $\beta$-blockers should be considered for most patients (class Ila, level B recommendation)

Angiotensin-receptor blockers may be considered to reduce hospital admissions because of heart failure (class lla, level B recommendation)

$\beta$-Blockers, ACE inhibitors, calcium-channel blockers and digoxin may be considered to minimize symptoms of heart failure (class Ilb, level C evidence)

*Class I = evidence or general agreement that a given procedure or treatment is beneficial, useful and effective; class II = conflicting evidence or a divergence of opinion about the usefulness or efficacy of the procedure or treatment; class Ila = weight of evidence is in favour of usefulness or efficacy; class Ilb = usefulness or efficacy is less well established by evidence or opinion; class III = evidence or general agreement that the procedure or treatment is not useful or effective and in some cases may be harmful; level A evidence = data derived from multiple randomized clinical trials or meta-analyses; level $\mathrm{B}$ evidence = data derived from a single randomized clinical trial or nonrandomized studies; level C evidence = consensus of opinion of experts and/or small studies. 
found that exercise was associated with an average improvement of 295 feet in the 6-minute walk test (range 135-455 feet).

We found 1 randomized trial, described in 2 articles, ${ }^{48,49}$ of a disease-management program for patients with diastolic and systolic heart failure. The intervention consisted of a proprietary disease-management protocol in which disease managers contacted patients (first weekly, then monthly) and made recommendations in accord with the guidelines for heart failure of the American College of Cardiology and American Heart Association. ${ }^{9}$ Patient education was also provided. The trial found that the intervention had no effect on mortality or quality of life in the predefined subgroup of 317 patients with diastolic dysfunction.

Overall with respect to nonpharmacologic therapy, we conclude that, based on a single small study, exercise programs may be helpful in reducing symptoms in patients with diastolic heart failure, especially older women.

\section{The case revisited}

It is reasonable for the clinician to make sure the patient's hypertension continues to be well controlled, aiming for a blood pressure of less than 140/90 mm Hg. Furosemide should be used to control pulmonary congestion and peripheral edema. A cardiac rehabilitation program that encourages physical activity may improve her exercise tolerance. Patient education is recommended for all patients with heart failure and should

Table 3: Evidence-based information on the use of candesartan to treat diastolic heart failure*

\begin{tabular}{|c|c|}
\hline Variable & Information \\
\hline Starting dose & $4 \mathrm{mg} / \mathrm{d}$ \\
\hline Target dose & $32 \mathrm{mg} / \mathrm{d}$ \\
\hline $\begin{array}{l}\text { Frequency of upward } \\
\text { titration }\end{array}$ & Every 2 weeks \\
\hline Contraindicationst & $\begin{array}{l}\text { - Current serum creatinine level } \\
>265 \mathrm{mmol} / \mathrm{L} \\
\text { - Current serum potassium level } \\
>5.5 \mathrm{mmol} / \mathrm{L} \\
\text { - History of marked hyperkalemia } \\
\text { from use of } \mathrm{ACE} \text { inhibitor } \\
\text { resulting in either serum } \\
\text { potassium level } \geq 6.0 \mathrm{mmol} / \mathrm{L} \text { or } \\
\text { life-threatening adverse event } \\
\text { - Known stenosis of renal artery } \\
\text { bilaterally } \\
\text { - Current symptomatic } \\
\text { hypotension }\end{array}$ \\
\hline $\begin{array}{l}\text { Reasons for } \\
\text { discontinuation }\end{array}$ & $\begin{array}{l}\text { - Hypotension } \\
\text { - Increase in serum creatinine level } \\
\text { - Hyperkalemia }\end{array}$ \\
\hline
\end{tabular}

*This was the only medication found to have clinical benefit in a large randomized trial in patients with diastolic heart failure. Other angiotensinreceptor blockers are not included because we did not assume a class effect. Also, the target dose and titration frequency are not established for other angiotensin-receptor blockers in the treatment of diastolic heart failure. tFrom the CHARM-Preserved study. ${ }^{37}$ be provided. ${ }^{1}$ The clinician may find the educational modules from the Heart Failure Society of America ${ }^{50}$ to be useful. Finally, the clinician could consider adding or switching to an angiotensin-receptor blocker to reduce symptoms, while monitoring for possible adverse effects including hypotension, worsening renal function and hyperkalemia (Table 3 ).

\section{Gaps in knowledge}

Our systematic review of the most recent literature has confirmed that there is still a paucity of effective therapies for diastolic heart failure. As well, many of the studies included both patients with systolic heart failure and patients with diastolic heart failure. Moreover, there is still disagreement over the definition of diastolic heart failure.

Our review has several limitations. First, because the definition and diagnostic criteria of diastolic heart failure are still debated, the condition may be labelled differently by various study authors. Our search strategy could have thus failed to identify applicable trials. To safeguard against this possibility, we also scrutinized the reference lists of review articles for high-quality randomized controlled trials or meta-analyses that may not have been included in our search results. Second, the inclusion criteria used by the trials we found were heterogeneous. Different cut-off values, ranging from $40 \%$ to $50 \%$, were used to define left ventricular ejection fraction. In 5 of the 14 studies, patients without diastolic dysfunction documented by echocardiography were excluded. Two trials evaluating ACE inhibitors and $\beta$-blockers included only patients with a history of myocardial infarction, which raises concern that these medications may have benefited patients for reasons other than treatment of their diastolic heart failure. Despite the heterogeneity of the studies, we are reassured by the fact that their results were predominately homogeneous in finding limited effectiveness in existing therapies.

\section{Clinical implications}

Clinicians who have patients with diastolic heart failure should understand that treatment of the disease cannot be based solely on evidence from randomized trials. Despite large trials of angiotensin-receptor blockers, ACE inhibitors, $\beta$-blockers and digoxin, none has shown a reduction in mortality. It would therefore be reasonable for clinicians to treat diastolic heart failure with angiotensin-receptor blockers, based on evidence showing a reduction in the rate of hospital admissions because of heart failure as a secondary outcome. Clinicians should be mindful, however, of the potential for hypotension, increased creatinine levels and hyperkalemia when using angiotensin-receptor blockers.

This article has been peer reviewed.

Competing interests: None declared.

Contributors: Katina Tzanetos, Derek Leong and Robert Wu conceived the study. All of the authors participated in the systematic review of the literature. Derek Leong and Robert Wu abstracted and summarized the results. Katina Tzanetos drafted the article. All of the authors revised it critically for important intellectual content and approved the final version submitted for publication. 
Acknowledgement: We acknowledge the help of our librarian, Jessie McGowan, for advising us on our search strategy and for executing the search.

\section{REFERENCES}

1. Arnold JM, Liu P, Demers C, et al. Canadian Cardiovascular Society consensus conference recommendations on heart failure 2006: diagnosis and management Can J Cardiol 2006;22:23-45.

2. Gaasch WH, Zile MR. Left ventricular diastolic dysfunction and diastolic hear failure. Annu Rev Med 2004;55:373-94.

3. Bhatia RS, Tu JV, Lee DS, et al. Outcome of heart failure with preserved ejection fraction in a population-based study. N Engl J Med 2006;355:260-9.

4. Zile MR, Baicu CF, Bonnema DD. Diastolic heart failure: definitions and terminology. Prog Cardiovasc Dis 2005;47:307-13

5. Zile MR, Brutsaert DL. New concepts in diastolic dysfunction and diastolic heart failure. Part I: diagnosis, prognosis, and measurements of diastolic function. Circulation 2002;105:1387-93.

6. Wu EB, Yu CM. Management of diastolic heart failure - a practical review of pathophysiology and treatment trial data. Int J Clin Pract 2005;59:1239-46.

7. Banerjee P, Banerjee T, Khand A, et al. Diastolic heart failure: Neglected or misdiagnosed? J Am Coll Cardiol 2002;39:138-41.

8. Thomas MD, Fox KF, Coats AJ, et al. The epidemiological enigma of heart failure with preserved systolic function. Eur J Heart Fail 2004;6:125-36.

9. Hunt SA, Abraham WT, Chin MH, et al. ACC/AHA 2005 Guideline update for the diagnosis and management of chronic heart failure in the adult: a report of the American College of Cardiology/American Heart Association Task Force on Practice Guidelines (Writing Committee to Update the 2001 Guidelines for the Evaluation and Management of Heart Failure): developed in collaboration with the American College of Chest Physicians and the International Society for Heart and Lung Transplantation: endorsed by the Heart Rhythm Society. Circulation 2005 112:e154-235.

10. How to diagnose diastolic heart failure. European Study Group on Diastolic Heart Failure. Eur Heart J 1998;19:990-1003.

11. Vasan RS, Levy D. Defining diastolic heart failure: a call for standardized diagnostic criteria. Circulation 2000;101:2118-21.

12. Ho KK, Pinsky JL, Kannel WB, et al. The epidemiology of heart failure: the Framingham Study. J Am Coll Cardiol 1993;22(Suppl A):6A-13A.

13. Owan TE, Redfield MM. Epidemiology of diastolic heart failure. Prog Cardiovasc Dis 2005;47:320-32.

14. Braunwald E. Shattuck lecture - cardiovascular medicine at the turn of the millennium: triumphs, concerns, and opportunities. N Engl J Med 1997;337:1360-9.

15. Liao L, Jollis JG, Anstrom KJ, et al. Costs for heart failure with normal vs reduced ejection fraction. Arch Intern Med 2006;166:112-8

16. Vasan RS, Larson MG, Benjamin EJ, et al. Congestive heart failure in subjects with normal versus reduced left ventricular ejection fraction: prevalence and mortality in a population-based cohort. J Am Coll Cardiol 1999;33:1948-55.

17. Redfield MM, Jacobsen SJ, Burnett JC Jr, et al. Burden of systolic and diastolic ventricular dysfunction in the community: appreciating the scope of the heart failure epidemic. JAMA 2003;289:194-202.

18. Kitzman DW, Gardin JM, Gottdiener JS, et al.; Cardiovascular Health Study Research Group. Importance of heart failure with preserved systolic function in patients $>$ or $=65$ years of age. Cardiovascular Health Study. Am J Cardiol 2001;87 413-9.

19. Devereux RB, Roman MJ, Liu JE, et al. Congestive heart failure despite norma left ventricular systolic function in a population-based sample: the Strong Heart Study. Am J Cardiol 2000;86:1090-6.

20. Kupari M, Lindroos M, Iivanainen AM, et al. Congestive heart failure in old age: prevalence, mechanisms and 4-year prognosis in the Helsinki Ageing Study. J Intern Med 1997;241:387-94.

21. Sanderson JE. Heart failure with a normal ejection fraction. Heart 2007;93:155-8.

22. Shammas RL, Khan NU, Nekkanti R, et al. Diastolic heart failure and left ventricular diastolic dysfunction: What we know, and what we don't know! Int J Cardiol 2007; 115:284-92.

23. Chen HH, Lainchbury JG, Senni M, et al. Diastolic heart failure in the community: clinical profile, natural history, therapy, and impact of proposed diagnostic criteria. $J$ Card Fail 2002;8:279-87.

24. Vasan RS, Benjamin EJ, Levy D. Prevalence, clinical features and prognosis of diastolic heart failure: an epidemiologic perspective. J Am Coll Cardiol 1995;26:1565-74

25. Owan TE, Hodge DO, Herges RM, et al. Trends in prevalence and outcome of heart failure with preserved ejection fraction. N Engl J Med 2006;355:251-9.

26. Senni M, Redfield MM. Heart failure with preserved systolic function. A different natural history? [review]. J Am Coll Cardiol 2001;38:1277-82
27. Little WC, Brucks S. Therapy for diastolic heart failure. Prog Cardiovasc Dis 2005; $47: 380-8$

28. Hogg $\mathrm{K}$, McMurray $\mathrm{J}$. The treatment of heart failure with preserved ejection fraction ("diastolic heart failure"). Heart Fail Rev 2006;11:141-6.

29. Massie BM, Fabi MR. Clinical trials in diastolic heart failure. Prog Cardiovasc Dis 2005;47:389-95.

30. Pfeffer MA, Braunwald E, Moye LA, et al. Effect of captopril on mortality and morbidity in patients with left ventricular dysfunction after myocardial infarction. Results of the Survival and Ventricular Enlargement trial. The SAVE Investigators. N Engl J Med 1992;327:669-77.

31. Dargie HJ. Effect of carvedilol on outcome after myocardial infarction in patients with left-ventricular dysfunction: the CAPRICORN randomised trial. Lance 2001:357:1385-90

32. Cleland JG, Tendera M, Adamus J, et al. PEP-CHF I. The perindopril in elderly people with chronic heart failure (PEP-CHF) study. Eur Heart J 2006;27:2338-45.

33. $\mathrm{Zi} \mathrm{M}$, Carmichael N, Lye M. The effect of quinapril on functional status of elderly patients with diastolic heart failure. Cardiovasc Drugs Ther 2003;17:133-9.

34. Yip GW, Wang M, Wang T, et al. The Hong Kong diastolic heart failure study: a randomised controlled trial of diuretics, irbesartan and ramipril on quality of life, exercise capacity, left ventricular global and regional function in heart failure with a normal ejection fraction. Heart 2008;94:573-80.

35. Lang CC, McAlpine HM, Kennedy N, et al. Effects of lisinopril on congestive heart failure in normotensive patients with diastolic dysfunction but intact systolic function. Eur J Clin Pharmacol 1995;49:15-9.

36. Aronow WS, Kronzon I. Effect of enalapril on congestive heart failure treated with diuretics in elderly patients with prior myocardial infarction and normal left ventricular ejection fraction. Am J Cardiol 1993;71:602-4.

37. Yusuf S, Pfeffer MA, Swedberg K, et al. CHARM Investigators and Committees Effects of candesartan in patients with chronic heart failure and preserved left-ventricular ejection fraction: the CHARM-Preserved Trial. Lancet 2003;362:777-81.

38. Flather MD, Shibata MC, Coats AJ, et al. Randomized trial to determine the effect of nebivolol on mortality and cardiovascular hospital admission in elderly patients with heart failure (SENIORS). Eur Heart J 2005;26:215-25.

39. Aronow WS, Ahn C, Kronzon I. Effect of propranolol versus no propranolol on total mortality plus nonfatal myocardial infarction in older patients with prior myocardial infarction, congestive heart failure, and left ventricular ejection fraction > or $=40 \%$ treated with diuretics plus angiotensin-converting enzyme inhibitors. Am J Cardiol 1997;80:207-9.

40. Takeda Y, Fukutomi T, Suzuki S, et al. Effects of carvedilol on plasma B-type natriuretic peptide concentration and symptoms in patients with heart failure and preserved ejection fraction. Am J Cardiol 2004;94:448-53.

41. Ahmed A, Rich MW, Fleg JL, et al. Effects of digoxin on morbidity and mortality in diastolic heart failure: the ancillary digitalis investigation group trial. Circulation 2006;114:397-403.

42. Hung MJ, Cherng WJ, Kuo LT, et al. Effect of verapamil in elderly patients with left ventricular diastolic dysfunction as a cause of congestive heart failure. Int $J$ Clin Pract 2002;56:57-62.

43. Cohn JN, Johnson G. Heart failure with normal ejection fraction. The V-HeFT Study. Veterans Administration Cooperative Study Group. Circulation 1990;81(Suppl):III48-53

44. Ahmed A, Rich MW, Love TE, et al. Digoxin and reduction in mortality and hospitalization in heart failure: a comprehensive post hoc analysis of the DIG trial. Eur Heart J 2006;27:178-86.

45. Gary R. Exercise self-efficacy in older women with diastolic heart failure: results of a walking program and education intervention. J Gerontol Nurs 2006;32:31-9; quiz 40-1.

46. Gary RA, Sueta CA, Dougherty M, et al. Home-based exercise improves functional performance and quality of life in women with diastolic heart failure. Heart Lung 2004;33:210-8.

47. Gary R, Lee SY. Physical function and quality of life in older women with diastolic heart failure: effects of a progressive walking program on sleep patterns. Prog Cardiovasc Nurs 2007;22:72-80.

48. Smith B, Forkner E, Zaslow B, et al. Disease management produces limited qualityof-life improvements in patients with congestive heart failure: evidence from a randomized trial in community-dwelling patients. Am J Manag Care 2005;11:701-13.

49. Galbreath AD. KRS. Long-term healthcare and cost outcomes of disease management in a large, randomized, community-based population with heart failure. Circulation 2004;110:3518-26.

50. Heart Failure Society of America. Educational modules on heart failure. Saint Pau (MN): The Society. Available: www.hfsa.org/hf modules.asp (accessed 2009 Feb. 2).

Correspondence to: Dr. Robert Wu, Toronto General Hospital,

Rm. 14EN-222, 200 Elizabeth St., Toronto ON M5G 2C4;

robert.wu@uhn.on.ca 